Received: 2017.12.27 Accepted: 2018.02.15 Published: 2018.03.28

\section{Torsion of the Vermiform Appendix: A Case Report and Review of Literature}

Case Rep,

e-ISSN 1941-5923

DOI: $10.12659 / A J C R .908725$
Authors' Contribution:

Study Design A

Data Collection B

Statistical Analysis C

Data Interpretation D

Manuscript Preparation E

Literature Search F

Funds Collection G

\author{
ABCDEFG Wan Amir Wan Hassan \\ ABCDEF Yeng Kwang Tay \\ DE Marjan Ghadiri
}

Department of Surgery, Monash Health, Melbourne, Victoria, Australia
Corresponding Author: Conflict of interest:
Wan Amir Wan Hassan, e-mail: wanhassw@tcd.ie None declared

\begin{abstract}
Patient: Male, $\mathbf{3 0}$
Final Diagnosis: Torsion of appendix

Symptoms: Abdominal pain $\bullet$ anorexia $\bullet$ nausea

Medication: -

Clinical Procedure: Laparoscopic appendicectomy

Specialty: Surgery

Objective: Rare disease

Background: Torsion of the vermiform appendix is a rare condition that presents with symptoms analogous to those of common acute appendicitis; therefore, it is often diagnosed during surgery. It was first described by Payne et al. in 1918. Since then, there has been wide recognition of a primary and a secondary form of the condition, affecting both the pediatric and adult populations. We present a case of an adult patient and conducted a literature review in the adult demographic.

Case Report: We report the case of a 30-year-old man who presented with clinically acute appendicitis. Laparoscopically, we diagnosed a torsion of the vermiform appendix secondary to a mucocele process. Histology confirmed a lowgrade mucinous cystoadenoma, with a hemorrhagic necrosis of the wall, in keeping with torsion.

Conclusions: Torsion of the vermiform appendix is a rare condition that presents similar to acute appendicitis, and therefore is often diagnosed intraoperatively. Since first described, 33 cases in adults were identified in the English literature, and recognition of a primary or secondary form has emerged. Preoperative radiological imaging is rarely useful in diagnosis. To the best of our knowledge, this is the eighth reported case in the English literature of a torsion of the vermiform appendix secondary to a mucinous cystoadenoma.
\end{abstract}

MeSH Keywords: Appendix • Cystadenoma, Mucinous • Torsion Abnormality

Full-text PDF: https://www.amjcaserep.com/abstract/index/idArt/908725

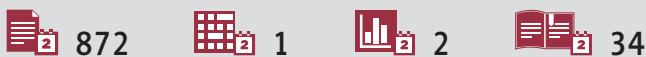




\section{Background}

Torsion of the vermiform appendix is a rare condition that presents with symptoms analogous to those of common acute appendicitis; thus, it is often diagnosed during surgery. It was first described by Payne et al. in 1918 [1]. Since then, there has been wide recognition of a primary and a secondary form of the condition, affecting both the pediatric and adult populations. We present a case of torsion of the vermiform appendix secondary to mucinous cystoadenoma, with a review of the literature in the adult demographic.

\section{Case Report}

A 30-year-old man presented with a 24-h history of progressive onset of abdominal pain associated with nausea and anorexia. The pain was localized centrally and migrated to the right iliac fossa. He reports there was no radiation of pain or any febrile symptoms. His bedside observations were within normal limits. Abdominal examination revealed significant tenderness with localized peritonism on the right iliac fossa. Rovsing's sign was also positive. Laboratory findings were unremarkable except for leukocytosis of $15.1 \times 10^{9} / \mathrm{L}$ (normal range 4.0-11.0). Radiological imaging was not performed, as he was clinically diagnosed with acute appendicitis.

Upon laparoscopy, the appendix was located in the right iliac fossa but was grossly distended and gangrenous in appearance (Figure 1). It was rotated 720 degrees anticlockwise at its base. A standard laparoscopic appendicectomy was performed with two 5-mm ports inserted at the left iliac fossa and suprapubic area. The appendix was assessed carefully and deemed appropriate to proceed laparoscopically, as it did not appear to be necrotic or at high risk of rupture with manipulation. Its position was paracecal, which did not require

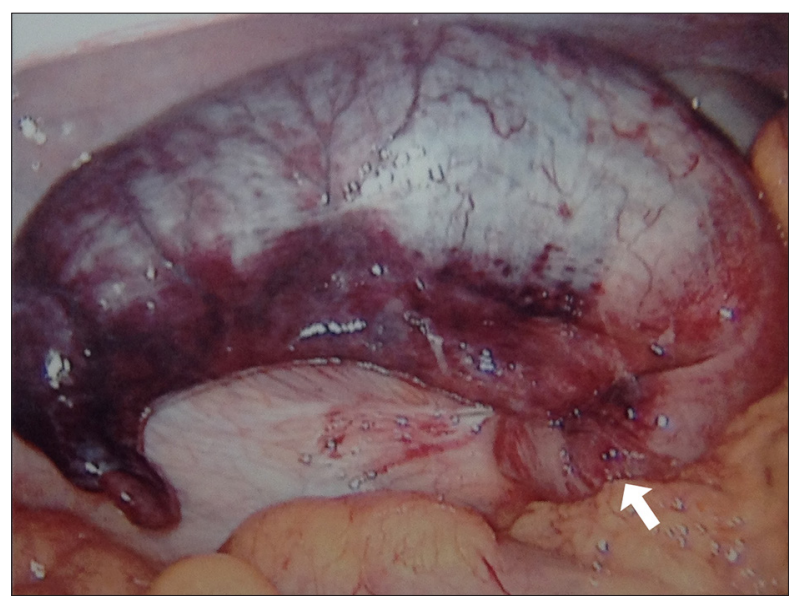

Figure 1. Laparoscopic view of the appendix mucocele. Arrow pointing to torsion at the base of the appendix.

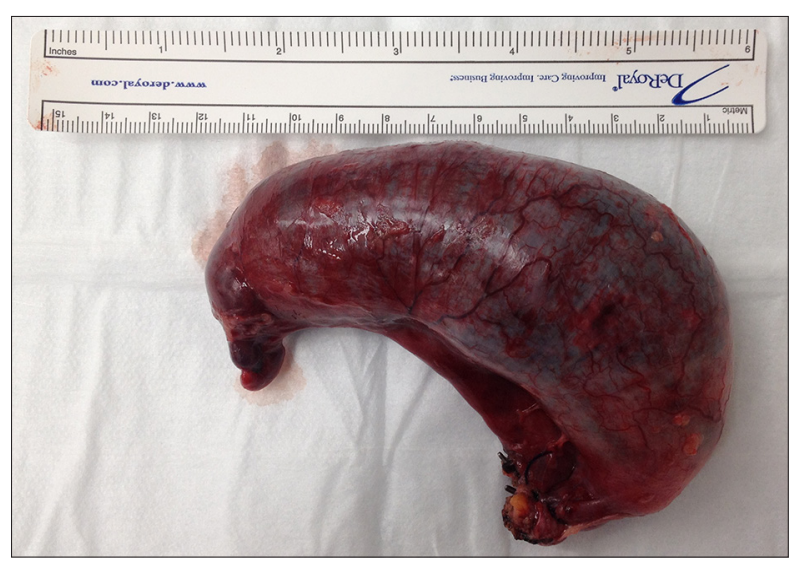

Figure 2. Appendix specimen.

significant laparoscopic manipulation to define the anatomy. The appendix was untwisted completely, and the mesoappendix was dissected with the appendiceal artery clipped and transected. The base of appendix was ligated using 2 loops of polydioxanone suture (PDS) and the appendix was retrieved using a specimen pouch plastic bag. The umbilical port site wound had to be extended inferiorly to deliver the specimen. The patient recovered post-operatively without any complications and was discharged home the next day. The specimen measured $120 \mathrm{~mm}$ in length, with a maximum diameter of $30 \mathrm{~mm}$ (Figure 2). Histology finding was a low-grade mucinous cystoadenoma, with a hemorrhagic necrosis of the wall, in keeping with torsion.

\section{Discussion}

Torsion of the vermiform appendix is a rare disorder that presents with a clinical picture similar to acute appendicitis; therefore, it is often diagnosed intraoperatively, to the surgeon's surprise. It was first reported in the English literature by Payne et al. in 1918 [1]. Since then, there has been widespread recognition of a primary and secondary form of appendiceal torsion.

In our review of the English literature, 33 cases of torsion of the vermiform appendix in adults were identified, including the present case [1-32] (Table 1). The mean age is 42 years old, with a range of 18 to 79 years old, and a 19: 14 femaleto-male sex ratio. The rotation of torsion varies from 180 to 1800 degrees, and although anticlockwise rotation is often reported as the most common rotation, our review of the literature in the adult population shows that clockwise rotation is most common (12 clockwise vs. 8 anticlockwise).

Primary torsion has been associated with anatomical variation in which the mesoappendix is fan-shaped, with a narrow base, and the absence of the azygotic fold that normally attaches the appendix laterally, or a long appendix $[33,34]$. It 
Table 1. Appendiceal torsion in an adult.

\begin{tabular}{|c|c|c|c|c|c|c|c|c|c|}
\hline \multirow{2}{*}{$\begin{array}{l}\text { Author } \\
\text { Payne JE }\end{array}$} & \multirow{2}{*}{$\begin{array}{l}\text { Ref } \\
{[1]}\end{array}$} & \multirow{2}{*}{$\begin{array}{l}\text { Year } \\
1918\end{array}$} & \multirow{2}{*}{$\begin{array}{c}\text { Age/Sex } \\
37 \mathrm{~F}\end{array}$} & \multirow{2}{*}{$\begin{array}{l}\text { Presenting } \\
\text { complain } \\
\text { RIF pain NV }\end{array}$} & \multicolumn{2}{|c|}{$\begin{array}{l}\text { Degree/direction } \\
\text { of torsion }\end{array}$} & \multirow{2}{*}{$\begin{array}{c}\text { Length, } \\
\text { cm } \\
7\end{array}$} & \multirow{2}{*}{$\begin{array}{c}\text { Preoperative } \\
\text { USS/CT/MRI } \\
\text { No }\end{array}$} & \multirow{2}{*}{$\begin{array}{c}\text { Secondary } \\
\text { cause } \\
\text { Fecalith }\end{array}$} \\
\hline & & & & & 1080 & NA & & & \\
\hline Bevers EC & {$[2]$} & 1920 & $35 \mathrm{~F}$ & RIF pain NV Fever & 720 & NA & 7.6 & No & \\
\hline Flatley G & [3] & 1936 & $22 \mathrm{~F}$ & $\begin{array}{l}\text { Periumbilical pain } \\
\text { NV Fever }\end{array}$ & 900 & NA & 9.5 & No & \\
\hline Chan KP & [4] & 1965 & $18 \mathrm{~F}$ & RIF pain & 1260 & NA & 10 & No & Simple mucocele \\
\hline Ghent WR & {$[5]$} & 1966 & $21 \mathrm{M}$ & RIF pain NV Fever & 450 & $A C$ & NA & No & \\
\hline De Bruin AJ & {$[6]$} & 1969 & $28 \mathrm{~F}$ & $\begin{array}{c}\text { Lower Abd Pain } \\
\text { Fever }\end{array}$ & 360 & $\mathrm{AC}$ & 10.5 & No & \\
\hline Killam AR & [7] & 1969 & $47 M$ & RIF pain NV Fever & NA & NA & 7 & No & $\begin{array}{l}\text { Mesoappendiceal } \\
\text { lipoma }\end{array}$ \\
\hline Legg NGM & [8] & 1973 & $29 M$ & RIF pain Fever & 360 & NA & 10 & No & Simple mucocele \\
\hline Finch DRA & [9] & 1974 & $38 \mathrm{~F}$ & RIF pain NV Fever & 360 & NA & NA & No & \\
\hline Cassie GF & [10] & 1953 & $25 \mathrm{M}$ & RIF pain N & 720 & $A C$ & 11 & No & Carcinoid tumor \\
\hline Petersen KR & [11] & 1982 & $59 \mathrm{~F}$ & Suprapubic pain NV & 540 & NA & 10 & No & \\
\hline Dickson DR & [12] & 1953 & $60 \mathrm{~F}$ & RIF pain NV & 720 & & 15 & No & Simple mucocele \\
\hline Won $\mathrm{OH}$ & [13] & 1977 & $35 M$ & RIF pain & NA & NA & 12 & No & \\
\hline Abu Zidan FM & [14] & 1992 & $32 \mathrm{~F}$ & RIF pain & NA & C & NA & USS & Simple mucocele \\
\hline Moten AL & {$[15]$} & 2002 & $44 \mathrm{~F}$ & Abd pain & 360 & $\mathrm{AC}$ & NA & No & $\begin{array}{c}\text { Mucinous } \\
\text { cystoadenoma }\end{array}$ \\
\hline Tzilinis A & [16] & 2002 & $44 M$ & Suprapubic pain NV & 540 & C & 5.5 & No & \\
\hline Bowling CB & [17] & 2006 & Middle age $F$ & Abd pain NV & NA & C & 12 & CT & $\begin{array}{c}\text { Mucinous } \\
\text { cystoadenoma }\end{array}$ \\
\hline Bestman TJR & [18] & 2006 & $35 \mathrm{~F}$ & Abd pain $N$ & NA & NA & 7.5 & USS & \\
\hline Rajendran N & [19] & 2006 & $29 \mathrm{~F}$ & RIF pain N & 360 & NA & 11 & No & Simple mucocele \\
\hline Rudloff U & [20] & 2007 & $28 \mathrm{~F}$ & RLQ pain & 900 & C & 5 & CT & Simple mucocele \\
\hline Kitagawa M & [21] & 2007 & $34 M$ & Periumbilical pain & 180 & C & 10 & CT & $\begin{array}{c}\text { Mucinous } \\
\text { cystoadenoma }\end{array}$ \\
\hline Hebert JJ & [22] & 2007 & $59 M$ & RLQ pain & NA & NA & 12 & CT & $\begin{array}{c}\text { Mucinous } \\
\text { cystoadenoma }\end{array}$ \\
\hline Hamada T & [23] & 2007 & $79 M$ & Abd pain & 180 & $A C$ & NA & USS & $\begin{array}{c}\text { Mucinous } \\
\text { cystoadenoma }\end{array}$ \\
\hline Wani I & [24] & 2008 & $76 M$ & RIF pain N & 540 & $A C$ & 10 & No & Fecalith \\
\hline Wani I & [25] & 2010 & $38 \mathrm{~F}$ & RIF pain NV fever & 180 & C & 20 & CT & $\begin{array}{c}\text { Adhesion from ovarian } \\
\text { mucocele torsion }\end{array}$ \\
\hline Lee CH & [26] & 2011 & $78 \mathrm{~F}$ & RIF pain NV & 900 & $A C$ & 10.5 & CT & Simple mucocele \\
\hline Marsdin EL & {$[27]$} & 2011 & $48 M$ & RIF NV & 360 & C & NA & No & \\
\hline Dimitriadis PA & {$[28]$} & 2012 & $52 \mathrm{~F}$ & RUQ pain & 540 & $A C$ & 9 & USS & Caecal malposition \\
\hline Mishin I & [29] & 2012 & $30 M$ & RIF pain, $\mathrm{N}$ & 360 & C & 11 & No & $\begin{array}{c}\text { Mucinous } \\
\text { cystoadenoma }\end{array}$ \\
\hline Stark C & [30] & 2014 & $34 \mathrm{~F}$ & RIF pain NV & 720 & C & 8 & US and MRI & $\begin{array}{c}\text { Mucinous } \\
\text { cystoadenoma }\end{array}$ \\
\hline Grebic D & [31] & 2015 & $70 M$ & RIF pain & 1800 & C & 9 & USS & $\begin{array}{l}\text { Mesoappendiceal } \\
\text { lipoma }\end{array}$ \\
\hline Dubhashi SP & [32] & 2016 & $52 \mathrm{~F}$ & RIF pain fever & 180 & C & 8 & USS & \\
\hline Current & & 2017 & $30 M$ & RIF pain & 720 & C & 12 & No & $\begin{array}{c}\text { Mucinous } \\
\text { cystoadenoma }\end{array}$ \\
\hline
\end{tabular}

F - Female; M - Male; RIF - right iliac fossa; NV - nausea vomiting; NA - not available; AC - anticlockwise; C - clockwise; USS - ultrasound scan; CT - computed tomography scan; MRI - magnetic resonance imaging; Ref - reference. Secondary causes, where clearly mentioned, are listed. Otherwise, it was left blank and presumed as primary torsion or undefined. 
has also been described as a secondary ischemic or necrotic change with luminal distension distally to the torsion site in the absence of any primary lesion.

Secondary torsion is associated with an identifiable pathology such as a fecalith, mucocele, carcinoid tumor, or cystoadenoma. Theoretically this would cause the appendix to first be engorged and distended, before rendering it unstable and more likely to twist.

Preoperative imaging is often unhelpful in diagnosis. Out of the 33 reported cases in adults, 13 had preoperative imaging that is not a plain film, and of those, only 3 reported cases had a radiologically diagnosed twisted appendix [22,23,30]. Hamada et al. described a target-like appearance at the base of the appendix on ultrasound akin to that seen in cases of ovarian and testicular torsion, whereas in the case reported by Herbert et al., a whorl of mesenteric fat and vessels around the appendiceal axis was seen on CT. On MRI, Stark et al. considered mesenteric edema and abrupt tapering of the base of appendix to be signs of torsion.

\section{References:}

1. Payne JE: A case of torsion of the appendix. Br J Surg, 1918; 6: 327

2. Bevers EC: Torsion of the appendix. Lancet, 1920; 1: 597

3. Flatley G: Torsion of the vermiform appendix associated with pregnancy. Lancet, 1936; 1: 1357

4. Chan KP: Volvulus complicating mucocele of the appendix. Br J Surg, 1965; 52: 713-14

5. Ghent WR, Carnovale BV: Primary volvulus of the appendix. Can Med Assoc J, 1966; 95: 926-27

6. De Bruin AJ: Torsion of appendix. Med J Aust, 1969; 1: 581

7. Killiam AR: An unusual case of appendicitis: Torsion produced by a mesoappendiceal lipoma. Ann Surg, 1969; 35: 648-49

8. Legg NGM: Torsion complicating mucocele of appendix. J R Coll Surg Edinb, 1973; 18(4): 236

9. Finch DRA: Torsion of appendix. Br J Clin Pract, 1974; 28(11): 391-92

10. Cassie GF: Torsion of mucocele of the appendix caused by a carcinoid tumor. Br J Surg 1953; 41(165): 105-6

11. Petersen KR, Brooks L, Pedersen $H$ : Torsio appendicis vermiformis. Report of an unusual case. Acta Chir Scand, 1982; 148(4): 383-84

12. Dickson DR, Jennings WK: Mucocele of the appendix complicated by torsion and gangrene. Calif Med, 1953; 79(4): 317-18

13. Won OH, Waxman M: Torsion of vermiform appendix JAMA, 1977; 237(13): 1312-13

14. Abu Zidan FM, al-Hilaly MA, al-Atrabi N: Torsion of a mucocele of the appendix in a pregnant woman. Acta Obstet Gynecol Scand, 1992; 71(2): 140-42

15. Moten AL, Williams RS: Torsion of the appendix. Med J Aust, 2002; 177(1112): 632

16. Tzilinis A, Vahedi MH, Wittenborn WS: Appendiceal torsion in an adult: Case report and review of literature. Curr Surg, 2002; 59(4): 410-11

17. Bowling CB, Lipscomb GH: Torsion of the appendix mimicking ovarian torsion. Obstet Gynecol, 2006; 107(2 Pt 2): 466-67

18. Bestman TJR, van Cleemput M, Detournay G: Torsion of the vermiform appendix: A case report. Acta Chir Belg, 2006; 106(2): 228-29

19. Rajendran N, Ameen S, Rohatgi A: Laparoscopic management of a torted appendix. Ann R Coll Surg Engl, 2006; 88(6): W6-7

\section{Conclusions}

Torsion of the vermiform appendix is a rare condition that presents similar to acute appendicitis and is therefore often diagnosed intraoperatively. Since first described, 33 cases in adults were identified in the English literature, and recognition of a primary or secondary form has emerged. Preoperative radiological imaging is rarely useful in diagnosis. To the best of our knowledge, the present case is the eighth report in the English literature of a torsion of the vermiform appendix, secondary to a mucinous cystoadenoma. Whether surgery is carried out in open or laparoscopic approach, great care should be taken to avoid iatrogenic rupture of the appendiceal mucocele. We would not hesitate to convert to open to prevent iatrogenic rupture and spillage of content/cystadenoma in a more difficult situation.

\section{Conflict of interest}

None.

20. Rudloff U, Malhotra S: Volvulus of an appendiceal mucocele: Report of a case. Surg Today, 2007; 37(6): 514-17

21. Kitagawa M, Kotani T, Yamano T et al: Secondary torsion of vermiform appendix with mucinous cystadenoma. Case Rep Gastroenterol, 2007; 1(1): 32-37

22. Hebert JJ, Pickhardt PJ: MDCT diagnosis of an appendiceal mucocele with acute torsion. Am J Roentgenol, 2007; 189(1): W4-6

23. Hamada $\mathrm{T}$, Kosaka $\mathrm{K}$, Shigeoka $\mathrm{N}$ et al: Torsion of the appendix secondary to appendiceal mucocele: Gray scale and contrast-enhanced sonographic findings. J Ultrasound Med, 2007; 26(1): 111-15

24. Wani I, Kitagawa M, Rather $M$ et al: Torsion of vermiform appendix with fecalith: A case report. Cases J, 2008; 1(1): 20

25. Wani I, Maqbool M, Sheikh T: Secondary torsion of vermiform appendix. J Emerg Trauma Shock, 2010; 3(2): 206-7

26. Lee CH, Lee MR, Kim JC et al: Torsion of a mucocele of the vermiform appendix: A case report and review of the literature. J Korean Surg Soc, 2011; 81(Suppl.1): S47-50

27. Marsdin EL, Griffiths C: Primary torsion of vermiform appendix mimicking acute appendicitis. BMJ Case Rep, 2011; 2011: pii: bcr0320113979

28. Dimitriadis PA, Makar RR, Randall JK, Ramus J: Appendiceal torsion associated with undescended caecum: A case report and review of the literature. BMJ Case Rep, 2012;2012: pii: bcr2012006932

29. Mishin I, Ghidirim G, Zastavnitsky G, Popa C: Torsion of an appendiceal cystadenoma. Report of a case and review of literature. Ann Ital Chir, 2012 83(1): 75-78

30. Stark C, Jousi M, Enholm B: Preoperative assessment and treatment of appendiceal mucocele complicated by acute torsion: A case report. BMC Res Notes, 2014; 7: 1

31. Grebic D, Lovasic F, Benjak I, Lovasic I: Secondary torsion of vermiform appendix with mesoappendiceal lipoma. Ann Saudi Med, 2015; 35(2): 173-75

32. Dubhashi SP, Khadav B: Appendicular torsion. Niger J Surg, 2016; 22(1): 41-42

33. Dewan PA, Woodward A: Torsion of the vermiform appendix. J Pediatr Surg, 1986; 21(4): 379

34. Sarin YK, Pathak D: Torsion of vermiform appendix. Indian Pediatr, 2006; 43(3): 266-67 